\title{
Acción colectiva y subjetividad. Un balance desde los estudios sociales
}

\author{
Collective action and subjetivity. a balance \\ from social studies
}

\author{
Alfonso Torres Carrillo1
}

\section{Resumen}

Los movimientos sociales han sido constitutivos de las sociedades y de las ciencias sociales contemporáneas; tanto que hoy constituyen uno de los campos de investigación más prolíficos de los estudios sociales. El artículo hace una revisión crítica del lugar que han tenido las dimensiones subjetivas de la acción colectiva, entre los diferentes enfoques teóricos sobre los movimientos sociales. Además, presenta y documenta la emergencia de la subjetividad como campo problemático y perspectiva interpretativa en los estudios sociales contemporáneos. A partir de este balance, se plantea un modelo analítico para abordar procesos organizativos y de movilización social en contextos urbanos, destacando el peso de aspectos subjetivos presentes en ellos.

\section{Palabras clave}

Movimientos sociales, acción colectiva, subjetividad, imaginario cultural, representaciones sociales.

\section{Abstract}

Social movements have contributed to shape societies and contemporary Social Sciences, so much that this topic constitutes one of the more prolific fields of research in Social Studies. This article provides a critical review of the place that the dimensions of collective action have had within the different theoretical perspectives about social movements. In addition, this paper presents and documents the emergence of subjectivity as a problematic field of interpretation in contemporary social studies. From this balance, an analytical model is proposed to address organizational processes and social mobilization in urban settings, emphasizing the relevance of subjective aspects in them.

\section{Keywords}

Social movements, collective action, subjectivity, cultural imaginary, social representations.

Artículo recibido el 30 de julio de 2009 y aprobado el 16 de octubre de 2009

1 Doctor en Estudios Latinoamericanos. Docente e investigador de la Universidad Pedagógica Nacional. actualmente, Coordinador del grupo de investigación: Sujetos y Nuevas Narrativas en Investigación y Enseñanza de las Ciencias Sociales, y de la Maestría en Estudios Sociales de la misma universidad. Correo electrónico: atorres@pedagogica.edu.co 


\section{Presentación}

Los movimientos sociales, así como los intentos por explicarlos, han sido constitutivos de las sociedades y las ciencias sociales contemporáneas. Por un lado, han sido decisivos en la consolidación de los estados modernos, la construcción de los sistemas democráticos, la expansión de la sociedad civil y la ampliación de la ciudadanía. La organización y la movilización colectiva han sido un mecanismo eficaz de los sectores subalternos en los dos últimos siglos para visibilizar conflictos, injusticias y exclusiones sociales, así como para impugnar las arbitrariedades de los gobernantes y las consecuencias adversas de la expansión del capital; en efecto, la historia contemporánea no podría comprenderse sin estas luchas contra los autoritarismos y otras formas de presión y discriminación social.

Por otra parte, el estudio de estas luchas sociales y de los conflictos que las originan ha sido constitutivo del campo de las ciencias sociales, en particular de la sociología y el análisis político. Las convulsiones sociales y políticas generadas a partir de las revoluciones francesa e industrial atrajeron la atención de los pensadores sociales y las nacientes disciplinas sociales que buscaron explicarlas; sus fundadores, asombrados frente a la proliferación de revoluciones, levantamientos, motines y huelgas, buscaron "descubrir" las leyes que las explicaran, ya fuera para controlar o encauzar el movimiento de lo social. En la medida en que el abanico de formas de acción colectiva se fue ampliando en el transcurso del siglo XX, las ciencias sociales también fueron expandiendo sus perspectivas para describirlas e interpretarlas; así fueron surgiendo diferentes enfoques teóricos para abordarlas, llevando a que el estudio de los movimientos sociales sea hoy en día un campo intelectual autónomo en disciplinas como la sociología, la historia social, la ciencia política y la psicología social.

Desde finales del siglo XIX y mediados del siguiente, en el marco de los grandes sistemas teóricos, se construyeron enfoques interpretativos de los movimientos sociales que buscaron explicar su emergencia, continuidad y capacidad de transformación de las estructuras sociales en las que se enmarcan. Pese a que los paradigmas epistemológicos predominantes hasta la segunda posguerra orientaron la atención de los científicos sociales hacia los factores sistémicos, estructurales y objetivos (Wallerstein, 1996), la presencia de dimensiones de carácter subjetivo fue ineludible. Así se les consideraran "variables dependientes" o aspectos determinados por factores y procesos "objetivos", categorías como conciencia, ideología, descontento, inconformidad, creencias generalizadas y agravio moral no son extraños en la literatura especializada sobre el tema.

Más aún, a partir de la década del setenta del siglo XX, la tendencia predominante en los estudios y tendencias conceptuales sobre movimientos sociales ha sido la de atribuirle un papel cada vez mayor a estas dimensiones simbólicas y de producción de significado en la comprensión de la acción colectiva (Tejerina, 1998, p. 111). Desde la tradición anglosajona como desde el llamado paradigma de la identidad, se incorporaron categorías y claves interpretativas relacionadas con la cultura, los marcos interpretativos, la producción simbólica, los imaginarios y las representaciones y las significaciones sociales.

Dicha renovación en los estudios sobre movimientos sociales coincide con un movimiento más amplio en las ciencias sociales -llamado "el giro cultural"- que llevó a que la subjetividad se haya convertido en una perspectiva para abordar el conjunto de la vida social. Este creciente interés por involucrar la producción simbólica y de sentido en el análisis social está asociado, por una parte, a la proliferación de luchas y procesos sociales que reivindican explícitamente dimensiones subjetivas o incorporan la acción cultural; por la otra, con los efectos de las epistemologías interpretativas y constructivistas en disciplinas y campos de estudio como los estudios culturales y los estudios subalternos. Esta nueva perspectiva comienza a impactar la investigación sobre acción colectiva y movimientos sociales contemporáneos, en particular, los latinoamericanos, en los cuales el peso de los imaginarios culturales, la memoria colectiva, las tradiciones, el simbolismo, las creencias compartidas y la configuración de identidades es ineludible.

El propósito de este artículo es hacer un balance de los principales aportes conceptuales provenientes de los dos campos de estudio señalados: por un lado, los estudios sobre movimientos sociales (en sus diferentes enfoques); por el otro, el campo emergente 
en torno a la subjetividad, a su vez transversalidad y a las diferentes disciplinas y áreas de estudio. Como dice Tejerina: (1998, p. 112)

El reconocimiento de la producción simbólica llevada a cabo por los movimientos sociales y su incidencia en el cambio de valores del orden social en el que actúan, no ha conducido a un análisis sistemático de sus dimensiones y características.

Finalmente, esbozaré algunos desafíos al estudio de la dimensión subjetiva en los diferentes planos y dinámicas de la acción colectiva.

\section{Acercamientos a lo subjetivo desde los enfoques sobre movimientos sociales La tradición marxista}

El marxismo fue el pionero en abordar los movimientos sociales, en particular el movimiento obrero, dada la centralidad que el materialismo histórico y la teoría socialista le dio a la clase proletaria como sujeto de transformación revolucionaria. En sentido estricto, los fundadores del materialismo histórico no desarrollaron una teoría de los Movimientos Sociales; sin embargo, su concepción crítica de la historia del capitalismo, así como el análisis de algunas coyunturas y experiencias de lucha obrera en el siglo XIX, incorporaron perspectivas interpretativas para el análisis de los movimientos sociales. Desde el propósito de valorar el potencial emancipador de estas luchas sociales en el advenimiento del socialismo, los fundadores del marxismo centraron su interés en explicarlas en relación con las contradicciones estructurales del capitalismo, al carácter de clase de sus protagonistas y a su contribución a la revolución social (Marx y Engels, 1970; Marx, 1975; Marx, 1978).

Si bien es cierto que la acción colectiva buscó ser explicada desde las determinaciones estructurales, por la dinámica histórica de la "lucha de clases", y no por la voluntad particular de los individuos y colectivos sociales, se reconoció que el potencial revolucionario de la acción colectiva estaba asociado a la existencia de la conciencia de clases; es decir, que las clases dominadas reconozcan su interés estratégico; por ejemplo, el de los proletarios es destruir el sistema de dominación capitalista (Harnecker, 1980, p. 182).
La formación de una conciencia de clase es la que garantizaría el tránsito de "clase en sî" a "clase para sí”, lo que supone la crítica a la ideología dominante y la adopción de una ideología revolucionaria.

Pese a que los estudios de Marx sobre las luchas sociales de su época dieron cuenta de las múltiples determinaciones y potencialidades de su historicidad (Marx, 1975 y 1978), y que pensadores marxistas como Antonio Gramsci y George Luckas cuestionaron todo reduccionismo mecanicista, la tendencia ortodoxa en los estudios marxistas sobre las luchas y movimientos clasistas han sido deterministas, historicistas y reduccionistas. Por un lado, las causas de la acción colectiva, la identidad de sus actores y su conciencia están "objetivamente" determinados por las estructuras sociales; en segundo lugar, las luchas y movimientos se presentan como expresión de una dirección histórica única; en tercer lugar, la acción colectiva es vista como una unidad homogénea, descuidando las dinámicas de su construcción.

Finalmente, esta perspectiva dogmática del materialismo histórico genera una comprensión reduccionista de los procesos subjetivos presentes en los movimientos, de los sentidos que constituyen y se constituyen en la acción colectiva. La "unidad" del actor social como clase también se expresa en la comprensión monolítica de sus motivaciones, ideologías, de su conciencia social y sus utopías, como puede verse en la siguiente afirmación tomada de un manual de materialismo histórico de amplia influencia en América Latina: "la conciencia de clase es objetiva y racional” (Harnecker, 1980, p. 183).

Estas versiones deterministas de los movimientos sociales fueron cuestionadas y superadas desde la propia tradición marxista. En particular durante la segunda mitad del siglo XX, un grupo de historiadores ingleses, a partir de sus investigaciones sobre las luchas campesinas y obreras, renovaron la comprensión histórica de los movimientos sociales. Militantes de izquierda a la vez que rigurosos y prolíficos investigadores, George Rudé, Eric Hosbawm y Edward Thompson incorporaron nuevas claves analíticas para la comprensión de la acción colectiva desde sus propios protagonistas(Casanova, 1991).

En la perspectiva de hacer una "historia desde abajo" sobre la protesta popular en Francia e Inglaterra, Rudé elabora conceptos como "multitud", ideología inherente e ideología derivada (Rudé, 1980 y 1984). Con el primero, denomina los conjuntos 
sociales que protagonizan las protestas revueltas y levantamientos populares, reconociéndoles la posesión de objetivos, ideologías y motivaciones propias. Identificada la multitud y los factores que explican las causas de la protesta; el autor valora la necesidad de escrudiñar el origen y curso de las ideas y motivaciones de sus protagonistas. Influido por Gramsci, Rudé plantea que las “ideología popular" de los movimientos no puede verse como "conciencia de clase", sino como una mezcla entre sus valores, creencias e ideas tradicionales, la "ideología inherente", y los recursos ideológicos provenientes desde fuera e incorporados y adaptados por la gente: la "ideología derivada” (Rudé, 1984).

Por otra parte, Thompson (1986), en su monumental estudio sobre la formación de la clase obrera inglesa y en sus reflexiones metodológicas, incorporó categorías como sujeto, cultura, identidad, experiencia y economía moral. Partiendo de los presupuestos según los cuales la actividad histórica es un diálogo abierto entre preguntas, material empírico y conceptos, y que el marxismo no es un dogma teórico, sino una perspectiva interpretativa, en sus estudios historiográficos evidenció la tensión dialéctica entre estructuras, procesos y sujetos históricos y ratifico que es más desde su cultura y su experiencia que desde la conciencia como los grupos sociales perciben y actúan sobre su realidad:

Con la experiencia, los hombres y mujeres devienen como sujetos, como personas que experimentan las situaciones productivas y las relaciones dadas en que se encuentran, en tanto que necesidades e intereses y en tanto que antagonismos, elaborando luego su experiencia desde las coordenadas de su conciencia y de su cultura por las vías más complejas y actuando luego a su vez sobre su propia situación (a menudo, pero no siempre, por medio de las estructuras de clase (Thompson, 1981, p. 253).

Por otro lado, Thompson cuestiona las posturas que ven en los motines de subsistencia simples reacciones espasmódicas a los estímulos económicos, pues desconocen que los insumisos poseían sus propios criterios culturales para justificar su acción: defendían derechos y costumbres ancestrales de sus comunidades que fueron desconocidos. A ese conjunto de valores y creencias, desde los cuales los pobres estiman unas relaciones y prácticas sociales como legítimas o no, las denominó “economía moral" (Thompson, 1984, p. 66).

\section{De la psicología de masas a la frustración relativa}

A comienzos del siglo XX, la perspectiva más influyente para explicar la emergencia de los grandes movimientos de base popular en Europa fue la llamada "psicología de masas" planteada por Gustave le Bon en 1895 (con ecos posteriores en Freud, Ortega y Gasset y Canetti). Por masa entendía "una reunión cualquiera de individuos, de cualquier nacionalidad, profesión o sexo, así como las circunstancias que los reúnen" (citado por Neveu, 2000, p. 48). En la masa, el individuo pierde su autonomía y sufre contagio de las creencias y comportamientos colectivos; por eso es sugestionable, emotiva y manipulable, por tanto, imprevisible y peligroso.

Así, para Le Bon existe una relación directa entre fenómenos grupales y cambio cognitivo. Al conformarse en colectivo, sean cual fueren sus integrantes, surge un "modo de pensar, sentir y actuar de modo diferente de la forma como lo haría cada uno por separado"; por un lado, surge un sentimiento de potencia invencible, que lleva a que, en el anonimato de la masa, los individuos abandonen todo sentimiento de responsabilidad; por el otro, se genera una dinámica de sugestibilidad que contagia a todos sus integrantes a actuar de un modo común. El conocimiento de la "psicología de masas" se presentaba como necesario para los estadistas y dirigentes políticos, "no tanto para gobernarlas, como para no ser gobernado por ellas" (Le Bon, 1986); en efecto, la obra de Le Bon fue consultada por dirigentes de derecha y de izquierda en Europa y América Latina durante la primera mitad del siglo XX2.

Frente a la traumática experiencia del ascenso de movimientos y regímenes políticos totalitarios en Europa, en la posguerra surgieron estudios sobre el consentimiento y la amplia participación popular en dichos procesos. Así, surgió una lectura crítica de la sociedad de masas, desde perspectivas como las de Hanna Arent (1973), Erich From y William Kornhauser. Sin la pretención de detenernos en

2 Un siglo después, el libro se ha traducido a más de dieciséis idiomas y se ha publicado en más de cincuenta ediciones diferentes. 
cada uno de sus planteamientos, basta con afirmar la preocupación común acerca de la manera en que en las sociedades de masas pierden fuerza y significado algunas instituciones y organizaciones como la familia, la escuela y los partidos que servían para regular las relaciones entre el individuo y la sociedad, siendo remplazadas por espacios y dinámicas de aglomeración social con escasa interacción entre los individuos y difusas formas de organización, proclives a la manipulación.

Por otra parte, los primeros estudios sociológicos sobre movimientos sociales desarrollados en los Estados Unidos han estado influidos por el funcionalismo y sus variantes; desde los trabajos pioneros de Park (1939) y Blumer (1957), quien acuñó la expresión "comportamiento colectivo", hasta culminar en los trabajos más sistemáticos de Smelser (1962) y Gurr (1970), el paradigma pluralista del consenso, que ha dominado la tradición norteamericana.

Aunque los primeros autores, los cuales se ocuparon de los movimientos sociales en el marco de una interpretación funcionalista, vieron en ellos una expresión de conductas desviadas protagonizadas por individuos con dificultades de integración social en situaciones de malestar (Park, 1939), fue Smelser (1963) quien elaboró una teoría sobre el "comportamiento colectivo", en la que desempeñan un papel clave de ciertas dimensiones subjetivas. En primer lugar, hay que decir que Smelser entiende esta categoría como "una movilización basada en una creencia que redefine la acción social” (Smelser, 1995, p. 20) y en la que caben diversas formas de acción colectiva que van desde formas elementales, como el pánico, el furor colectivo y el estallido hostil, hasta comportamientos organizados, como los movimientos normativos y los movimientos valorativos.

La acción colectiva es siempre fruto de una tensión que conmueve el equilibrio del sistema social; dicha tensión, dada la incertidumbre y ansiedad que genera, lleva a que se acuda a creencias generalizadas, que incitan a acciones para restablecer el orden perdido. Éstas son valoraciones de la situación, anhelos y expectativas, desde las cuales se vuelve significativa la situación adversa generada por la tensión y se evalúa la pertinencia y orientación a la acción colectiva. En todos los grupos humanos existen creencias compartidas que no necesariamente se convierten en detonadoras de la acción colectiva; son determinantes cuando existen las condiciones de conductividad y tensión estructural, ya que son el factor necesario para que se dé la movilización colectiva. En todos los casos, las creencias buscan reestructurar una situación ambigua que ha generado la tensión estructural y que no puede manejarse en los marcos de acción existentes.

Por otro lado, Smelser retoma como criterio para explicar y describir los comportamientos colectivos los cuatro componentes básicos de la acción social (Smelser, 1995, p. 21): 1. Los valores, que proveen las orientaciones más amplias de los comportamientos; 2. Las reglas, o procedimientos reguladores de la interacción que inciden en la búsqueda de tales metas; 3. La movilización de la motivación individual para la acción organizada; 4 . Los instrumentos de la situación que el actor utiliza como medios para alcanzar metas concretas.

De estos componentes el autor deriva su tipología de comportamientos colectivos, según el principio por el cual cada uno se orienta hacia un componente distinto de la acción social (Smelser, 1995, p. 22):

1. Un movimiento valorativo es la acción colectiva, movilizada por una creencia generalizada que preconiza una reconstitución de valores. Por templo, el movimiento anticolonial liderado por Gandhi o el ambientalismo.

2. Un movimiento normativo es la movilización organizada en nombre de una creencia generalizada que propende a la reconstrucción de las normas. Por ejemplo, el movimiento antisegregacionista de Luther King.

3. El estallido hostil es la acción movilizada de acuerdo con una creencia generalizada, que asigna a algún agente la responsabilidad o culpa de un estado de cosas adverso, como el caso de los linchamientos a autoridades o especuladores.

4. El furor y el miedo pánico son formas de comportamiento basadas en una redefinición generalizada de las facilidades de la situación: un tumulto o revuelta posterior a un partido de futbol.

Pese a los cuestionables presupuestos funcionalistas y a la amplitud de la categoría de comportamiento colectivo, considero que la incorporación del concepto de creencia generalizada, como clave 
interpretativa para mediar la relación entre condiciones estructurantes y acción colectiva, es un aporte significativo en la construcción de una perspectiva que dé a los procesos subjetivos un papel importante en la comprensión de los movimientos sociales.

Finalmente, nos ocuparemos de Ted Gurr, quien, en su libro ¿Why men rebel?3, desarrolló un marco analítico para abordar la acción colectiva desde un enfoque psicosocial. Su concepto central es frustración relativa, entendida como "un estado de tensión, una satisfacción esperada y rechazada, generadora de potencial de descontento y de violencia" (Néveu, 2000 , p. 56). La frustración relativa surge del saldo negativo de la tensión entre los valores (materiales o inmateriales) que un individuo posee en un momento dado y las expectativas frente a aquellos que siente que tiene derecho; es relativa porque depende de una lógica de comparación entre dos situaciones cambiantes en el tiempo o el espacio. El siguiente ejemplo puede ilustrar el planteamiento: un grupo social como los criollos americanos en el siglo XVIII que, pese a mejorar sus condiciones materiales y considerar que tiene derecho a tener un lugar más decisivo en la esfera política, se ven impedidos en lograrlo, pueden sentir más frustración que otros sectores más pobres, pero que no aspiran a acceder al poder político.

Partiendo del reduccionismo sicológico que marca su propuesta, Gurr elabora un marco de posibles situaciones y tipologías de frustración colectiva que ilustra con experiencias históricas contemporáneas. Sin embargo, el autor busca superar dicho reduccionismo, incorporando factores culturales y de memoria colectiva: ¿cuáles valores o símbolos han sido los que más frecuentemente convocan a la acción rebelde? ¿Se tiene mayor o menor tradición de movilización colectiva?; preguntas que pueden ilustrarse ampliamente con ejemplos como el recuerdo de Tupac Amaru o Emiliano Zapata en diferentes luchas sociales en Perú y México.

En el mismo sentido, Gurr (1973, p. 45) destaca la importancia de las dimensiones cognitiva y simbólica para promover o inhibir la movilización colectiva: la promoción de un movimiento social requiere una producción discursiva y simbólica que retome o produzca valores y significados que legitimen la "rebeldía"; asimismo, para quienes

3 Traducido al español por Editorial Trillas en 1973 bajo el título: ¿Por qué se rebelan los hombres? ejercen la autoridad, es primordial incidir sobre los valores que legitiman el orden y las expectativas de los dominados para evitar que sobrepasen el umbral de frustración. Por ello, vale la pena destacar que Gurr fue uno de los primeros autores en señalar la importancia de los medios de comunicación como activadores o inhibidores de la acción colectiva.

\section{La teoría del "agravio moral" de Barrington Moore}

En 1978, el sociólogo norteamericano Barrington Moore publica el libro La injusticia. Bases sociales de la obediencia y la rebelión, en el que se propone indagar "por qué y con tanta frecuencia las personas soportan ser víctimas de sus sociedades y por qué en otras ocasiones se encolerizan y tratan con toda su pasión y todas sus fuerzas, de hacer algo respecto de su situación" (Moore, 1996, p. 9), y qué relación guarda dicho comportamiento con sus ideas y sentimientos sobre justicia e injusticia. Para responder a este problema, el autor hace una exhaustiva revisión de poblaciones "pasivas" e insumisas en diferentes contextos y periodos históricos, así como de algunas teorías e investigaciones sociológicas y psicológicas.

Desde una posición crítica a todo determinismo -ya evidente en una obra previa-4, Moore articula dimensiones históricas, sociales, culturales y psicológicas para comprender la concurrencia de situaciones que los humildes consideran como inequitativas o injustas, pero que en unos casos aceptan y en otras rechazan. Para ello, incorpora la categoría de agravio moral definida como el sentimiento de indignación asociada al incumplimiento del "contrato social recurrente" en las relaciones entre elites y dominados; en otras palabras, "al fracaso para cumplir con sus obligaciones, expresas o implícitas, de proporcionar seguridad y organizar los propósitos colectivos" (Moore, 1996, p. 56); por ejemplo, la aplicación discriminada de las normas o la imposición de trabajos indeseables y de castigos desproporcionados. Tales límites de lo injusto no son universales, son construidos culturalmente.

4 “[...] Los seres humanos, individual y colectivamente, no reaccionan a una situación objetiva del mismo modo que una sustancia química reacciona a otra cuando se les mete juntas en un tubo de ensayo. Tal forma del behaviorismo estricto constituye un craso error. Entre la gente y una situación objetiva media siempre unas variables -un filtro, cabría decir-compuestas de toda suerte de anhelos, esperanzas y otras ideas procedentes del pasado" (Moore, 1973, p. 686). 
"Las fórmulas culturales definen las necesidades sociales aceptables o inaceptables, el significado y las causas del sufrimiento humano y aquello que los individuos pueden o deben hacer respecto del sufrimiento" (Moore, 1996, p. 85).

Frente a la pregunta sobre por qué hombres y mujeres no se rebelan ante condiciones "objetivamente" opresivas u oprobiosas, caso más común en la historia que la insumisión, su respuesta es social: para los grupos dominantes, es importante inhibir la capacidad de indignación de la gente, antes que acallar las demandas de injusticia. Distingue cuatro procesos que inhiben esfuerzos colectivos para identificar y resistir a las causas humanas del dolor y el sufrimiento: 1 . Temor a las represalias, activa una solidaridad colectiva entre los oprimidos frente a quien se rebela; 2. Destrucción de los lazos sociales previos entre aquellos que sufren, debilitando el mutuo apoyo; 3. La cooptación; 4. Fragmentación de la población afectada, ya sea por razones étnicas, de género, clase o religión.

Por otro lado, comprender cuándo la gente rechaza la opresión y se rebela implica considerar los procesos sociales, culturales y sicológicos que la llevan a cuestionar la inevitabilidad de las situación o la legitimidad de su existencia. En cuanto a lo social, la construcción de una presencia sólida y efectiva desde la conformación de procesos organizativos y de identidad colectiva, proceso que se da a mediano y largo plazo. En cuanto a lo cultural, el desafío es la creación de un criterio moral independiente del que legitima la opresión: "para cualquier grupo oprimido, la primera tarea consiste en sobreponerse a la autoridad moral que sostiene las causas del sufrimiento, y así crear una identidad política efectiva". En este proceso confluyen tres aspectos importantes (Moore, 1996, p. 95):

1. Invertir las formas de solidaridad a favor del opresor para reorientarlo en su contra.

2. Creación de patrones de condena para explicar y juzgar los sufrimientos actuales: redefinición del diagnóstico y el remedio.

3. Nueva definición de los amigos y los enemigos.

En últimas, lo importante es reconocer cómo los grupos sociales superan la anestesia social y el sentimiento de inevitabilidad de la situación y los sustituyen por el sentimiento de injusticia. En el plano social, venciendo la dependencia por medio de la creación de nuevas formas de solidaridad y de redes de cooperación y reorientarlas hacia el movimiento reivindicador. En el plano cultural, venciendo la ilusión de que el estado de cosas es inevitable, y fortaleciendo sentimientos morales de indignación: "la historia de todas las luchas políticas importantes refleja el choque de pasiones, convicciones y sistemas de creencias" (Moore, 1996, p. 443). Además de una masa potencialmente descontenta, se requiere activistas que articulen las demandas, cuestionen la mitología dominante y encausen la iniciativa rebelde; "ningún movimiento social ha podido existir sin su ejército de predicadores y militantes que esparcen las buenas nuevas sobre la necesidad de escapar de los males de este mundo" (Moore, 1996, p. 446).

\section{El eclipse de lo subjetivo: la elección racional y la movilización de recursos}

Otros enfoques actuales frente a la acción colectiva parten de desconfiar tanto del objetivismo de las categorías marxistas como del énfasis subjetivista de la teoría de la perspectiva del "comportamiento colectivo". Esta toma de distancia con las comprensiones estructurales y psicosociales de los movimientos sociales generó un nuevo reduccionismo: el de racionalidad económica como clave para explicar su sentido y organización. Las teorías de la decisión racional o racional choice (Olson, 1964; Elster 1979 y 1989) y de la movilización de recursos o resource mobilization (Obershall, 1973, Tilly, 1995) parten de la premisa de los protagonistas de la acción colectiva son "actores racionales" que actúan desde una racionalidad estratégica movida por la ecuación costo-beneficio. Los teóricos de ambas escuelas enfatizan variables "objetivas", como la organización, los intereses, los recursos, los repertorios y las estrategias de protesta y las estructuras de oportunidades.

El trabajo pionero de Olson (1964) introduce el cálculo de intereses estrictamente individuales para explicar el comportamiento de la gente en las organizaciones sociales. Por ello, sostiene que sin incentivos selectivos (perspectiva de beneficios materiales individuales) o sin restricciones (temor al castigo), el individuo racional no contribuye con sus recursos en la organización de la acción colectiva de grupos grandes; será más racional abstenerse de cooperar y dejar que otros hagan el trabajo: 
El miembro individual de una organización grande está en situación similar a la de la empresa en un mercado competitivo o al de un contribuyente: sus esfuerzos no producirán un efecto perceptible en la situación de la organización, de modo que puede disfrutar de cualquiera de las mejoras conseguidas por otros, haya o no trabajado para apoyar a su organización (Olson, 1964, p. 26).

Frente a las razones adversas a la participación, sin incentivos selectivos o sin amenazas, la acción colectiva se vuelve imposible o irracional (Cohen, 1995, p. 27). En fin, para Olson, la tendencia de los miembros de los grupos grandes es a no organizarse para la acción coordinada, así tengan razones para ello. Sin embargo, como la evidencia histórica muestra lo contrario y la gente sí participa de movimientos colectivos, los teóricos de la movilización de recursos coinciden en reconocer que Olson se equivoca al asumir que quienes se movilizan o no en una acción colectiva son individuos aislados (modelo del mercado); en la realidad, están ya organizados en grupos solidarios, en comunidades viables o en asociaciones en torno a "intereses colectivos".

Así, el modelo propuesto por Olson explica por qué algunos individuos no se vinculan a organizaciones o a los movimientos colectivos o buscan beneficiarse con el trabajo de los otros ("gorrones"), pero no da cuenta de quienes lo hacen. Tampoco, el individualismo metodológico da cabida a nociones como el altruismo, la cooperación, la solidaridad desinteresada o el compromiso con valores ajenos a la racionalidad instrumental de acuerdo a fines. El mismo Elster, en publicaciones recientes, ha tenido que admitir que la acción colectiva es resultado de diferentes motivaciones:

Varias clases de motivaciones pueden unirse y combinarse para producir una acción colectiva. No hay ninguna motivación privilegiada para la conducta cooperativa en todas las ocasiones, $\mathrm{ni}$ en una situación dada podemos esperar hallar un tipo de motivación que suministre la principal explicación de una acción colectiva coronada por el éxito (Elster, 1991, p. 66).

Los teóricos de la "movilización de recursos" centran la atención en la acción organizada; no se preguntan por qué los individuos se vinculan o no a las asociaciones, sino por la eficacia de sus acciones organizadas: ¿cómo se desencadena, se desarrolla y triunfa o fracasa una movilización? (McKarthy y Zald, 1977, p. 23). Su iniciador, Obershall, parte de la premisa de la continuidad entre el comportamiento normalizado y el no conformista. Las conductas institucionalizadas, al igual que los comportamientos colectivos, obedecen a la misma racionalidad (costo-beneficio) y por tanto pueden ser analizados desde nociones e instrumentos comunes. La acción social es asumida como creación, consumo e intercambio de recursos entre grupos y sectores de la sociedad; recurso es cualquier bien o valor (material o no) reconocido por tal, por uno o más grupos de la sociedad (Melucci, 1977, p. 97).

Los conflictos colectivos son vistos como luchas por el control de recursos y el énfasis de su análisis está en la organización que estructura al grupo y a los recursos para la movilización. Esta hace referencia al proceso de formación de las masas, de los grupos, de las asociaciones y organizaciones para satisfacer necesidades compartidas. A veces, se forman unidades sociales duraderas con dirigentes, legalismos, identidades y objetivos comunes (Obershall, 1973, p. 102). La movilización colectiva es un modo de obtener e invertir recursos para obtener determinados fines; cada grupo calcula costos y beneficios ligados a diversas opciones de acción; la participación o el liderazgo en un movimiento social puede ser analizados como formas de distribución de recursos, mediante los cuales los diversos actores calculan costos y beneficios, buscando obtener la máxima ventaja (Cohen, 1995, p. 25).

En la perspectiva de este artículo, podemos afirmar que los enfoques de decisión racional y movilización de recursos, así hayan hecho aportes en los aspectos organizacionales y estratégicos de los movimientos sociales, desconocieron la dimensión subjetiva de la acción colectiva y empobrecieron el análisis de la pluralidad de los componentes culturales, ideológicos y motivacionales presentes en ella. A la vez, dejan sin respuesta los procesos de solidaridad y de identidad colectiva, así como los contenidos altruistas presentes en la acción colectiva.

\section{El "paradigma" de la identidad}

Frente a los límites del funcionalismo, el marxismo y la teoría de movilización de recursos algunos teóricos europeos para comprender los movimientos sociales -en particular, la creación de nuevos significados, solidaridades e identidades colectivas- han generado nuevas claves para interpretar la acción 
colectiva. Al tratar de dar cuenta de los conflictos y movilizaciones sociales iniciadas en los países centrales a partir la década del setenta, autores como Alain Touraine, Jurgen Habermas, Alberto Melucci y Francesco Alberoni han contribuido en la formación de un "nuevo paradigma" en el campo de estudio de los movimientos sociales.

Touraine (1978, p. 43) define los movimientos sociales como:

El accionar colectivo y organizado de un actor social que lucha contra un oponente por la dirección del presente histórico con capacidad de producir orientaciones socioculturales que le permitan lograr el control social de los recursos centrales de una sociedad determinada.

En este sentido, las orientaciones culturales no están desvinculadas del conflicto social y, por tanto, la construcción de identidad de los movimientos sociales es un hecho objetivo y no sólo simbólico o expresivo. En otras palabras:

Los actores colectivos contemporáneos ven que la creación de identidad supone un conflicto social en lo que se refiere a la reinterpretación de las normas, a la creación de nuevos significados y al desafío de la construcción social de los límites mismos de la acción pública, la privada y la política (Cohen y Arato, 2001, p. 574).

Fue su discípulo, Alberto Melucci, quien llevó más a fondo la nueva interpretación de los movimientos y de sus dimensión subjetiva. Frente al restringido concepto de "comportamiento colectivo", propone la categoría de "sistema de acción colectiva", definida por la presencia del conflicto y de la solidaridad, es decir, "por un sistema de relaciones que liga e identifica a aquellos que participan en él" (Melucci, 1976, p. 99). Así, la acción colectiva por excelencia son los movimientos sociales, los cuales implican una lucha entre dos actores sociales definidos por una solidaridad específica que se enfrentan por la apropiación y el destino de los recursos sociales.

En trabajos posteriores (1994 y 1995), Melucci centra la atención en los llamados "nuevos movimientos sociales" propios de las "sociedades complejas". En éstas crece la densidad de información y la diferenciación de las adscripciones asociativas de los individuos y la autonomía en la construcción de identidades, a la vez, que aumenta la necesidad de integración y de control cultural por parte del sistema. Los conflictos surgidos desde los ochenta, reflejan esta nueva contradicción, a la vez, que introducen nuevos rasgos a la acción colectiva: 1 . Evidencian que la emergencia de los conflictos tiene un carácter permanente, no coyuntural; 2. Expresan la tensión entre los sistemas institucionales de decisión y la sociedad civil; 3 . Sus temáticas son particulares; 4 . Sus actores son temporales; 5 . Poseen una transversalidad social y una globalidad espacial; 6. Revelan a la sociedad que estos problemas existen; 7. La acción de los movimientos son ellas mismas un mensaje y una alternativa para la sociedad; 8 . Dan un lugar central a la expresión simbólica; 9. No buscan principalmente metas materiales.

En este nuevo contexto, Melucci analiza los movimientos sociales como construcciones sociales orientados por fines, valores, creencias, decisiones, pero a la vez delimitados por las restricciones estructurales de las relaciones sociales. Su comprensión debe involucrar tanto sus dimensiones analíticas internas como el sistema de referencia en el que se halla. En consecuencia, para Melucci (1999), los movimientos sociales son construcciones sociales organizadas como "sistemas de acción", que involucran:

1. Conflicto: existencia de oposiciones estructurales que generan dos o más actores que compiten por los mismos recursos.

2. Identidad: capacidad de los actores para generar solidaridades y sentidos de pertenencia que les permita ser vistos como actor social.

3. Trasgresión de los límites del sistema: alternatividad política, social y cultural.

Son "sistema" en la medida en que se configuran como estructuras organizadas que garantizan cierta unidad y continuidad en el tiempo; son "acción" en la medida en que están orientados por objetivos, creencias, decisiones; construyen "identidad" en la medida en que construyen solidaridades y sentidos de pertenencia a su interior y comparten campos de oportunidades comunes. Desde esta perspectiva metodológica, el autor muestra la manera en que los conflictos actuales tienden a producirse en las 
áreas del sistema más ligadas a la producción de recursos simbólicos, informativos y de comunicación, al sistema de valores y normas que regulan las relaciones básicas de la gente consigo misma, con los otros y con la naturaleza (cuerpo, sexualidad, ambiente, deseos). Asimismo, estos nuevos movimientos no se orientan por una razón instrumental de acuerdo con fines, sino que son un fin en sí mismos; la forma del movimiento es mensaje; en fin, actúan sobre la dimensión simbólica expresiva de la acción social (Melucci, 1994 y 1999).

$\mathrm{Al}$ considerar los movimientos sociales como sistemas de acción y mensajes simbólicos que plantean formas alternativas de comprender los problemas sociales y organizarse para actuar sobre ellos (Melucci, 1989), también son fuentes de construcción de identidad colectiva, entendida como "una definición compartida e interactiva, producida por varios individuos (o por grupos a un nivel más complejo) que está relacionada con las orientaciones de la acción y con el campo de oportunidades y constricciones en las que ésta tiene lugar" (Melucci, 1995, p. 44).

\section{Los marcos de la acción colectiva}

En medio del debate entre la tradición anglosajona de movilización de recursos y el "paradigma de la identidad", en la década del ochenta, emerge en Estados Unidos una perspectiva de comprensión de los movimientos sociales, a partir del concepto del "análisis de marcos" (frame analysis), planteado por Erving Goffman en 1974. El análisis de marcos de la acción colectiva surge como resultado de un trabajo conjunto de un grupo de sociólogos ${ }^{5}$ que abordan los movimientos sociales "como agencias de significación colectiva que difunden nuevos sentidos en la sociedad" (Laraña, 1999, p. 88). "Enmarcar" fue un concepto introducido por Goffman (1974), que significa seleccionar determinados aspectos de la realidad percibida, destacando algunos aspectos para definir un problema particular, una interpretación causal, una evaluación moral y una recomendación (Entman, 1993); los "marcos" son esquemas de interpretación que permiten a los individuos ubicar, percibir, identificar y clasificar los acontecimientos ocurridos en un espacio de vida social y en el mundo en general (Goffman, 1974, p. 21).

5 David Snow, Robert Benford, William Gamson, Scott Hunt, Steven Worden y Burke Rochford.
En el estudio de la acción colectiva, un marco es:

El conjunto de creencias y significados orientados hacia la acción que legitiman las actividades de un movimiento social. El análisis de marcos enfatiza en la producción y difusión de elementos ideológicos y culturales durante el proceso de transformación de acción colectiva en movimiento social (Chihu, 2008, p. 10).

Los estudiosos de los marcos interpretativos han subrayado su función para negar o llamar la atención sobre una injusticia social o definir como impropio o inmoral, lo que antes se veía como natural. Los marcos de referencia para la acción colectiva orientan a los actores para evaluar un problema y evaluar los resultados de la movilización.

Un concepto central de este enfoque es el de "alineamiento de marcos" que da cuenta de los nexos de congruencia entre los motivos, intereses y creencias de los individuos con las intenciones, actividades e ideologías de los movimientos sociales. Es una condición necesaria para la vinculación y permanencia de las personas a la acción colectiva. Desde esta teoría se considera que existen procesos de "alineación de marcos", cuya explicación nos permite profundizar el concepto (Snow et ál., 2006, p. 31 y siguientes):

1. El "puente entre marcos", el cual se refiere a los enlaces que se establecen entre marcos para difundirlos y transformarlos. Son sentimientos comunes de personas que comparten injusticias y agravios pero carecen de una base organizativa; algún agente (interno $o$ externo) asume la iniciativa de convocar y reclutar adherentes para el movimiento.

2. La "amplificación de marcos", la cual se refiere a la activación o vigorización de un marco frente a una problemática o conjunto de situaciones. Los marcos a activar pueden ser valores (principios o relaciones a proteger) $\mathrm{o}$ creencias sobre el problema, sus causas, sus responsables, la necesidad de movilizarse y sobre las probabilidades de transformación.

3. La "extensión de marcos" ocurre cuando las ideologías, metas y actividades del movimiento no hallan relación con las creencias, valores e intereses de los individuos; por tanto, le corresponde ampliar las fronteras de sus marcos iniciales para enganchar potenciales adherentes. 
4. La "transformación de los marcos" se da cuando las metas, ideologías y actividades del movimiento son tan ajenos a la población, que es necesario redefinir el marco de valores, creencias del movimiento.

En una perspectiva histórica, en los movimientos sociales, se van configurando "marcos maestros" que actúan como modelos de "señalamiento, atribución, articulación y movilización de un conjunto amplio de movimientos sociales" (Chihu, 2006, p. 23). Un ejemplo contemporáneo es el "marco de los derechos humanos" que es referente de diversos movimientos como el de las feministas, los grupos étnicos, los ancianos, las víctimas de la violencia y el colectivo LGBT. Generalmente, los ciclos de protesta, entendidos como escalonadas de acción colectiva en unos determinados periodos o coyunturas, están asociados al surgimiento y a la vigencia de un marco maestro; su incorporación también trae consigo innovaciones estratégicas y tácticas en los movimientos.

Finalmente, el proceso de enmarcado en todo movimiento social trae consigo una construcción de identidades tanto de los protagonistas o militantes de los movimientos como de los antagonistas u oponentes del mismo y de los observadores o audiencias del contexto, neutrales o no, comprometidos con el movimiento, pero que pueden pasar a serlo. Así, desde los marcos de diagnóstico, de pronóstico y de motivación de la acción colectiva se van atribuyendo significados a los actores mencionados.

\section{Construcción simbólica de los movimientos sociales}

Terminamos este recorrido de corrientes que reivindican las dimensiones subjetivas de la acción colectiva con un conjuntos de autores que abordan los llamados "nuevos movimientos sociales" (Melucci, 1985; Offe, 1985; Johnston, Laraña y Gusfield, 1994; Torres, 2002); sus trabajos han sido publicados desde de la década del noventa y han retomado aportes teóricos provenientes del mundo anglosajón y del paradigma de la identidad en una perspectiva constructivista que se pregunta por la capacidad de los movimientos sociales para crear nuevos significados sociales. Este horizonte común no significa que sean una escuela o tendencia homogénea. Se trata de Joseph Gusfield (1994), Ron Eyerman (1998) y Enrique Laraña (1994 y 1999).
Para dar cuenta de luchas contemporáneas, como las protagonizadas por las mujeres, que reivindican la equidad de género, los homosexuales, los ambientalistas, los defensores de los animales y contra el abuso infantil, Gusfield retoma algunos aspectos de la tradición interaccionista del comportamiento colectivo y de la psicología de masas, teorías desechadas por los actuales estudiosos de los movimientos sociales; los cuales parten de una distinción entre teorías que consideran los movimientos como acciones organizadas y los que los ven a los movimientos sociales como portadoras de ideas y nuevos significados (Gusfield, 1994, p. 95). El movimiento obrero es el ejemplo paradigmático del primero con sus miembros afiliados a sus sindicatos, sus mandos y sus bases, con sus objetivos programáticos y sus acciones convencionales (huelgas, marchas el 1 de mayo); en contraste, está el de mujeres, cuya militancia no pasa necesariamente por la pertenencia a una asociación, sus múltiples escenarios y formas de actuación (desde lo cotidiano y el habla corriente hasta los grandes escenarios públicos).

El autor reconoce que esa distinción analítica no se da tajantemente en la realidad de los movimientos -que conjugan ambas modalidades-, pero que es útil para distinguir entre movimientos lineales y fluidos; los primeros se asumen como organizaciones para alcanzar ciertos objetivos concretos, desde los cuales evalúan sus acciones; los segundos se proponen transformar las formas de percibir la realidad y los valores colectivos frente a una problemática, actúan dentro y fuera de estructuras organizadas y se manifiestan por medio de múltiples acciones en espacios cotidianos.

Aunque difiere -del presupuesto de base- de las teorías de comportamiento colectivo, sí reivindica su planteamiento, según el cual pueden ser fuente de nuevos valores y normas sociales como semillero de nuevas instituciones sociales (Turner y Killan, 1986). Igualmente, retoma los aportes del interaccionismo en torno a los marcos de acción (Goffman, 1974), en particular, a la capacidad de los movimientos sociales para sensibilizar a la sociedad en su conjunto y en torno a los problemas y alternativas a los cuales actúan.

También retoma tres aspectos de la teoría de la sociedad de masas que permiten comprender los movimientos fluidos (Gusfield, 1994, p. 111). En primer lugar, que en la actualidad buena parte de la interacción humana no se da cara a cara, sino 
mediante formas indirectas como los medios de comunicación; en este sentido es válida la idea de sociedad como "público". En segundo lugar, la interacción social deja de estar mediada por instituciones y grupos organizados; así, la categoría "masa" es reivindicada, no para definir los colectivos sino los campos de acción. Por último, una audiencia de masas es más estandarizada y homogénea que las distinciones de clase, etnia o género; un mismo colectivo puede reconocerse y actuar unas veces como clase o grupo étnico, y en otras ocasiones como masa sin identidad propia. Estos aspectos refuerzan el carácter dramatúrgico de los movimientos sociales, en la medida en que emprenden acciones encaminadas a incidir sobre las audiencias; de ahí, la tendencia actual de realizar acciones "espectaculares" para atraer la atención de los medios.

Por otra parte, Ron Eyerman (1998), luego de reconocer el creciente interés en la cultura por parte de los estudiosos de los movimientos sociales y de hacer una síntesis de los aportes del enfoque de los marcos de acción colectiva, destaca la necesidad de articular los marcos de la experiencia individual con los que provienen de la cultura y la memoria colectiva. Finalmente, se centra en la importancia de las formas estéticas de la representación simbólica, desde lo que denomina la "praxis cultural" de los movimientos sociales, entendida como equivalente al desarrollo en el plano artístico de lo que otros han elaborado en el plano cognitivo.

Mientras que la praxis cognitiva se refiere a la formación de conciencia y el papel que en ella juegan los intelectuales de los movimientos, la praxis estética se centra en la contribución de lo estético a la construcción de significado y la formación de identidad colectiva en el seno de un movimiento social (Eyerman, 1998, p. 143).

Ello puede darse en dos niveles: uno que denomina prepolítico y otro explícitamente político. El primero está referido a las previas disposiciones que generan las subculturas artísticas en la generación de significados e identidades, como es el caso de culturas musicales como el rock o el punk. El segundo nivel es el del uso intencional de artefactos culturales (canciones, himnos, imágenes, comparsas) como herramientas de movilización y construcción de sentidos de pertenencia; es el caso de la Internacional o la canción protesta latinoamericana.
La praxis cultural de los movimientos también involucra el "rescate" o la "invención" de tradiciones y rituales del movimiento. Entiende la tradición como el conjunto de creencias o costumbres que pasa de generación a generación y que influye en la interpretación y orientación de la vida en común; los movimientos restauran la conciencia de la tradición y ponerla al servicio de sus causas y de su cohesión interna; el arte y las música transportan tradiciones en forma de imágenes y símbolos que ayudan a enmarcar la acción colectiva. Los rituales cumplen un papel similar, dado que son ceremonias predeterminadas que sirven para aglutinar a los participantes y actualizar su pertenencia al movimiento y a la amplia tradición de protestas y luchas sociales; ello es evidente en los actos del $1^{\circ} \mathrm{de}$ mayo, pero también en los rituales y celebraciones de los movimientos.

Finalizamos con la síntesis que realiza Enrique Laraña (1999), al reconstruir el concepto de movimiento social desde la convergencia de las perspectivas interaccionistas y constructivistas. Apoyándose en los planteamientos sobre los marcos de acción y en las ideas de Alberto Melucci, el autor concibe los movimientos como sistemas de acción, mensajes simbólicos y agencias de significación colectiva que a la vez que construyen identidad colectiva entre sus miembros y simpatizantes, difunden nuevos significados culturales al conjunto de la sociedad. Los movimientos desnaturalizan y ponen en debate las estructuras y relaciones sociales que sostienen el orden social, construyen nuevas significados alternativos a los predominantes y movilizan redes sociales en pos de la transformación de las condiciones injustas.

Asimismo, su carácter simbólico y reflexivo posibilita la unidad y continuidad en el tiempo de los movimientos sociales, rasgos que los distinguen de otras formas de acción colectiva. Su cohesión interna, "se manifiesta en que sus miembros comparten ideas comunes y tiene una conciencia colectiva, en sentimientos de pertenencia a un grupo y de solidaridad con sus miembros" (Laraña, 1999, p. 113). Su continuidad temporal, a diferencia de otros eventos de protesta y movilización ocasionales y esporádicas, es fruto de su conexión con procesos históricos y sociales de carácter más estructural, pero también de su capacidad, pero también de su capacidad de construir tradiciones, memorias, identidades y visiones de futuro compartidas. 


\section{La subjetividad como perspectiva interpretativa}

Con el balance hecho en la primera parte del artículo, es evidente que los procesos y elementos de carácter subjetivo -llámense ideología, conciencia, psicología colectiva, creencia generalizada, frustración, agravio moral, identidad, orientación cultural o marcos interpretativos-, son una dimensión ineludible en el estudio de los movimientos sociales.. A continuación, presentaremos cómo desde diversos campos de los estudios sociales la subjetividad empieza a dejar de ser vista como una variable dependiente de los procesos sociales a ser una dimensión estructurante de las estructuras, instituciones y prácticas sociales. El reconocimiento de este posicionamiento de la subjetividad como campo problemático y como perspectiva de los estudios sociales puede ser útil en el abordaje de la acción colectiva.

\section{Hacia un nuevo paradigma}

Desde el paradigma epistemológico positivistadominante en la investigación social en el transcurso del siglo XX- lo subjetivo no cabía ni en la ciencia (entendida como una actividad racional analítica y procedimental) ni en su objeto genérico - pues la realidad social, se consideraba como un orden estructurado objetivamente, regido por la causalidad y el determinismo-, ni mucho menos en el investigador (del que se esperaba objetividad y neutralidad valorativa). Lo subjetivo se asimilaba al subjetivismo, a lo irreal, a lo imaginario, lo fantasioso y la personalidad individual; en consecuencia, en el quehacer investigativo se le consideraba como fuente de error, como "ruido" a ser neutralizado, como lo ambiguo, lo perturbador (Torres, 2006).

Hoy sabemos que la objetividad, el universalismo, la racionalidad científica y sus procedimientos, así como las teorías sociales, son construcciones subjetivas; las prácticas investigativas están impregnadas de subjetividad, al igual que todo esfuerzo por pensarla:

Participando en las matrices sociales (que incluyen la ciencia y las culturas de las que formamos parte) adquirimos formas de comprender y participar, metáforas y parámetros, ejes cognitivos y destrezas específicas. La subjetividad y las relaciones sociales se organizan en el trazado de esas metáforas, de esos horizontes que generan presuposiciones y expectativas, configurando creencias, epistemologías cotidianas y visiones de futuro (Fried, 1994, p. 16).
En el abordaje de la subjetividad, como campo problemático de reflexión e investigación, confluyen diferentes campos de estudio (disciplinares o no), tradiciones teóricas y enfoques metodológico; también supone desmontar supuestos e imágenes que la asimilan al subjetivismo como posición epistemológica, o a lo individual (como interioridad o conciencia). La subjetividad, más que un problema susceptible de diferentes aproximaciones teóricas, es un campo problemático desde el cual podemos pensar la realidad social y el propio pensar sobre la misma. El primer problema es definirla más allá de los límites que imponen los parámetros de cada enfoque y marco disciplinar; así, algunos autores coinciden en asumir la subjetividad como una categoría de mayor potencial analítico y emancipador que otras como conciencia o identidad; por ejemplo, Boaventura de Sousa (1994, p. 123) la define como "espacio de las diferencias individuales, de la autonomía y la libertad que se levantan contra formas opresivas que van más allá de la producción y tocan lo personal, lo social y lo cultural".

Para Isabel Jaídar (2003, p. 55):

La subjetividad es un medio de demostración de las ciencias sociales e incluye el conocimiento, las construcciones simbólicas e imaginarias de aquellos saberes descalificados por el positivismo señalándolos de no racionalistas, como son los mágicos, míticos, religiosos y en fin, todas las construcciones imaginarias y simbólicas que perviven en todos los pueblos de la tierra, y que se inscriben en un registro que tiene un lazo entre lo simbólico, lo social y lo singular.

\section{Funciones y rasgos de la subjetividad}

La categoría de subjetividad nos remite a un conjunto de instancias y procesos de producción de sentido, por medio de las cuales los individuos y colectivos sociales construyen realidad y actúan sobre ella, a la vez que son constituidos como tales. Involucra un conjunto de imaginarios, representaciones, valores, creencias, lenguajes y formas de aprehender el mundo, conscientes e inconscientes, cognitivas, emocionales, volitivas y eróticas, desde los cuales los sujetos elaboran su experiencia existencial y sus sentidos de vida (Torres, 2000, p. 8).

De este modo, la subjetividad, cumple simultáneamente varias funciones: 1. Cognoscitiva, pues, como esquema interpretativo y valorativo, 
posibilita la construcción de realidades, como lecturas del mundo y como horizonte de posibilidad de lo real; 2. Práctica, pues desde ella los individuos y los colectivos orientan sus acciones y elaboran su experiencia; 3. Vincular, dado que se constituye, a la vez que orienta y sostiene los lazos sociales; y 4. Identitaria, pues aporta los materiales desde los cuales individuos y colectivos definen su identidad personal y sus sentidos de pertenencias sociales (Torres, 2006, p. 91).

También podemos identificar algunas cualidades de la subjetividad como son su carácter simbólico, histórico y social, así como su naturaleza vinculante, magmático, transversal, tensional y de alteridad. La subjetividad no se agota en lo racional ni en lo ideológico, sino que se despliega en el amplio universo de la cultura, entendida como "entramado de símbolos en virtud de los cuales los hombres dan significado a su propia existencia [...] en el cual pueden orientar sus relaciones recíprocas, en su relación con el mundo que los rodea y consigo mismos" (Geertz, 1987, p. 205). Como fuente de sentido y mediación simbólica precede y trasciende a los individuos; constituye su yo más singular y su sentido de pertenencia a un conjunto social. Su naturaleza simbólica implica que no se puede acceder a su comprensión, sino por medio de los múltiples lenguajes humanos. La racionalidad de la ciencia con su lenguaje analítico y abstracto, es insuficiente para atrapar la riqueza de las diferentes racionalidades que constituyen la subjetividad, teniendo más potentes para ello la poesía, la literatura, el cine, las artes plásticas, las tradiciones y sabidurías populares.

La subjetividad es siempre de naturaleza social e histórica. La subjetividad individual es una variante de procesos subjetivos más amplios, los cuales a su vez, están sostenidos por formaciones sociales específicas. Éstas, a su vez han sido creadas por sujetos históricos concretos y se mantienen por medio de dinámicas subjetivas enmarcadas en contextos históricos y sociales determinados. Como fenómeno sociocultural complejo y dinámico, la subjetividad también posee su propia historicidad; se hace y se deshace; puede ser transitoria o permanecer a lo largo del tiempo; por ello no está sometida a una evolución progresiva o una dirección única.

No es posible considerar la subjetividad como una realidad estática, suprahistórica o ahistórica como lo han pretendido algunos estudiosos con dimensiones subjetivas como el inconciente colectivo, las estructuras mentales o los imaginarios simbólicos. La subjetividad:
Siempre que no se aborde con criterios reduccionistas, representa una situación de confluencia de planos de realidad en que se puede rastrear cómo desembocan los microprocesos (por ejemplo de índole psicológica), así como la apertura hacia ámbitos sociohistóricos que se caracterizan por ser inclusivos de otros planos que pueden constituir el contexto particular del sujeto concreto que interese estudiar (Zemelman, 1996, p. 99).

Asumir la subjetividad como dimensión social histórica implica reconocer su carácter de producente y de producida. Por un lado, porque está estructurada por múltiples dinamismos históricos y culturales que la condicionan; por otra, porque es estructurante de dichos procesos sociales, transformándolos y abriendo posibilidades de desenvolvimiento histórico. La subjetividad:

No puede entenderse como un campo definido en términos de sus manifestaciones, ya sean conductuales, de expectativas o perceptivas, sino de modo más profundo, desde su misma dinámica constitutiva y constituyente: ello nos remite a campos de realidad más amplios (Zemelman, 1996, p. 104).

La subjetividad es siempre alteridad, es el lenguaje, la grupalidad, la historia y la cultura internalizada en cada sujeto. La subjetividad es siempre intersubjetividad. En lo individual están expresándose otras subjetividades, como lo planteó Bajtin en sus conceptos de polifonía y dialogismo, cuando alguien habla, están presentes muchas voces. En fin, el yo y el nosotros es inconcebible sin el otro y el ellos que mutuamente se configuran. Cada ser humano es el otro de los otros, como lo han advertido Ricoeur (1996) y Octavio Paz.

La subjetividad también es de naturaleza vincular, si entendemos el vínculo como esa estructura sensible, afectiva ideativa y de acción que nos une, nos "ata" a otro ser y con la cual el sujeto se identifica. Para Pichon Riviere (1985, p. 87), el vínculo es la condición material de nuestra constitución subjetiva; para él, la identificación no está planteada como identificación a una imagen sino a un rasgo de la estructura vincular que incluye modelos de significaciones sensibles, afectivas, ideativas y de acción y que luego el sujeto reproduce. El vínculo es el que intermedia y permite la inserción del 
sujeto al campo simbólico de la sociedad. El vínculo es una estructura bifronte posee una cara interna y otra externa. La subjetividad es, entonces, una "verdadera selva de vínculos".

\section{Subjetividades constituyentes}

Si bien es cierto que la subjetividad social cristaliza en instituciones, normas, costumbres, rituales y modos de hacer, su naturaleza es magmática, plástica, fluida, indeterminada. Esta elasticidad y fluidez magmática de la subjetividad explica su naturaleza dinámica, cambiante, su vocación liminal y su potencial de creación y novedad (Sánchez Capdequí, 1999, p. 21); no se rige por la lógica identitaria ni por la causalidad, y es difícilmente conocible desde los esquemas interpretativos analíticos, formales, propios de la tradición de pensamiento occidental y de la teoría social clásica (Castoriadis, 2003).

Al respecto, vale la pena destacar la distinción que hace Chanquía (1994, p. 42) a partir de su lectura de Zemelman, entre subjetividad estructurada y subjetividad emergente o constituyente; mientras la primera involucra los procesos subjetivos de apropiación de la realidad dada, la segunda abarca los imaginarios, las representaciones y otras elaboraciones cognoscitivas portadoras de lo nuevo, de lo inédito; ésta debe definirse contra aquella subjetividad estructural y, en algunas ocasiones, fuera de ella, pues ámbitos de la realidad silenciados con anterioridad, adquieren significación en el proceso de su constitución.

Por ello, la subjetividad no está circunscrita a un espacio y tiempo determinados sino que en ella se condensan diferentes escalas existenciales, espaciales y temporales. Por ejemplo, al abordar lo individual debe reconocerse las diferentes grupalidades, institucionalidades y estructuras sociales que lo constituyen; la subjetividad, como actualización del pasado es memoria; como apropiación del presente, es experiencia; y como construcción de posibilidades, es futuro:

Toda práctica social conecta pasado y futuro en su concreción presente, ya que siempre se mostrará una doble subjetividad: como reconstrucción del pasado (memoria) y como apropiación del futuro, dependiendo la constitución del sujeto de la articulación de ambas (Zemelman, 1996, p. 116).
La subjetividad es transversal a la vida social. No hay plano ni momento de la realidad social que pueda pensarse sin subjetividad. Está presente en todas las dinámicas sociales y en todos sus ámbitos: tanto en la vida cotidiana y los espacios microsociales como en las realidades macrosociales, tanto en la experiencia intersubjetiva diaria como en las instituciones sociales que estructuran una época o una determinada formación social. La subjetividad va más allá de los condicionantes de la producción económica y de los sistemas políticos y toca lo personal, lo social y lo cultural. Finalmente, la subjetividad es escenario y a la vez vehiculiza los conflictos sociales y políticos. Como instituida, por medio de ella, se legitiman los poderes hegemónicos y se garantiza la cohesión social; como instituyente, la subjetividad alimenta los procesos de resistencia y posibilita la emergencia de nuevos modos de ver, de sentir y de relacionarse que van contra el orden instituido y que pueden dar lugar a nuevos ordenes de realidad.

La naturaleza simbólica, histórico social, intersubjetiva, vincular, magmática, transversal y tensional de la subjetividad, confirma su irreductibilidad a cánones racionalistas y parámetros cientificistas; si bien sólo es posible de ser reconocida por medio de los modos de ver, actuar y representarse de los individuos y colectivos específicos que son sujetos a ella, sus sentidos no se reducen a estás manifestaciones. Para comprenderla es necesario reconocer la especificidad y relaciones de las múltiples dimensiones que la constituyen.

\section{Algunos materiales de la subjetividad}

Asumida la subjetividad como campo problemático y perspectiva de interpretación de procesos, prácticas, instituciones, relaciones, transformaciones e innovaciones sociales, surge la necesidad de reconocer los materiales de la que está hecha. En la subjetividad confluyen dimensiones culturales y psíquicas reconocidas desde diferentes disciplinas sociales y campos de estudio como la antropología, el sicoanálisis, la psicología social, la historia y los estudios culturales. Destaco algunos: los imaginarios culturales, las representaciones sociales, la memoria social, las creencias, las ideologías, el inconsciente, el pensamiento, los conocimientos, los valores, las emociones y los sentimientos, las voluntades $\mathrm{y}$ las visiones de futuro. 
Por el carácter del artículo, no es posible abordar cada una de estas dimensiones, condensadas en conceptos construidos por diferentes disciplinas y estudios sociales. Por ahora, me limito a esbozar la especificidad de dos conceptos, los imaginarios y las representaciones, dado que, por un lado, tienden a confundirse en el uso cotidiano e incluso en los propios ámbitos académicos y, por el otro, cobran cada vez mayor centralidad en los análisis sociales contemporáneos.

La categoría imaginario simbólico o imaginario cultural, o lo imaginario fue acuñada en la ciencias sociales por el antropólogo Gilbert Durand (1964 y 1971), a partir de la confluencia de la tradición iniciada por Karl Jung, Ernest Cassirer, Mircea Eliade y Gastón Bachelard en torno a sus estudios sobre el inconciente colectivo, el simbolismo, los mitos y la imaginación poética. El imaginario se define como un orden de sentido profundo que a modo de imagen o metáfora enmarca la cosmovisión de un amplio colectivo social; actúa a la manera de estructura cultural profunda en la cual se organizan el conjunto de símbolos y representaciones de dicho colectivo social. En palabras de Wuneneburger (2000, p. 10):

Lo imaginario representa el conjunto de imágenes mentales y visuales, organizadas por la narración mítica, por la cual una sociedad organiza y expresa simbólicamente sus valores existenciales y su interpretación del mundo frente a los desafíos impuestos por el tiempo y la muerte.

En la perspectiva de la acción colectiva, la imaginación cultural es un lugar desde el cual puede pensarse la creatividad social, el cambio histórico y el surgimiento de inéditas formas de actuación y organización social. Sobre la base del carácter magmático, indeterminado y plástico de lo social en su nivel imaginario, puede pensarse el cambio social y la posibilidad de nuevas institucionalidades que desborden el orden instituido (Sánchez Capdequí, 1999, p. 22). Los imaginarios nutren de sentido a los movimientos sociales, en la medida en que aportan el subsuelo de símbolos, mitos y razones profundas, desde lo cual se fundamenta la acción colectiva, así como también su horizonte utópico: sueños y visiones de futuro que la animan; finalmente el imaginario es religadota, es decir, alimenta y mantiene el vínculo (empatías y simpatías) entre sus bases, entre estas y sus líderes, y entre el movimiento y el conjunto social (Maffesoli, 1990).

Los imaginarios son, en esta perspectiva, las matrices profundas de las que se nutren simbólicamente las representaciones sociales. Dicha categoría ha sido construida principalmente desde la psicología social construccionista (Moscovisci, 1976; Jodelet, 1986; Ibáñez, 1994) según la cual desde la vida cotidiana se construye la realidad como representación y como práctica social. Las representaciones sociales se refieren a la manera en que los seres humanos aprenden los acontecimientos de la vida diaria, las características del ambiente, las informaciones que en él circulan y las personas del entorno (Jodelet, 1986). Así, las representaciones serían las unidades de sentido desde las cuales organizamos nuestro sentido común y el pensamiento práctico.

"Si bien es fácil captar la realidad de las representaciones sociales, no es nada fácil captar el concepto" (Ibáñez, 1994, p. 170), dado que es un concepto híbrido en el que confluyen tradiciones sociológicas, antropológicas y psicológicas. Moscovisci (1976) sostiene que las representaciones sociales son "un cuerpo organizado de conocimientos y una de las actividades psíquicas gracias a las cuales los hombres hacen inteligible su realidad, se insertan en un grupo y en una relación cotidiana de intercambios". Las representaciones, como estructuras de significación, son a la vez constituidas y constituyentes de la vida social; expresan las condiciones sociales, a la vez que las construyen. Son una fuente, junto a las narrativas biográficas y los vínculos sociales, de la configuración de identidades sociales (Giménez, 1996).

Las representaciones sociales están organizadas en torno a significaciones centrales que producen y reproducen creencias, normas e ideas que rigen la vida cotidiana y colectiva de una sociedad. De este modo, las representaciones poseen una dimensión cognitiva (traen a la mente conceptos e interpretaciones), una normativa (atribuye un orden a lo social) y una simbólico-semiótica (significan lo que acontece); que van más allá del ámbito individual y presencial, al inscribirse en procesos colectivos de larga duración (Bonilla y García 1998, p. 20).

Finalmente, las representaciones sociales son irreductibles a otras formas de conocimiento como los imaginarios, los mitos, las ideologías o las creencias, así guarden relaciones estrechas y compartan 
aspectos de todas ellas. Por ello, queda planteada la necesidad de continuar definiendo los límites conceptuales de otras categorías constitutivas de la subjetividad, así como su consideración como dimensiones presentes en la acción colectiva. Ya varios estudios empíricos sobre movimientos sociales en América Latina han evidenciado la importancia de considerar dichas realidades subjetivas para comprender la especificidad de movimientos como el de los indígenas en Bolivia (Tejeiro, 2007), Mexico (Gadea, 2004) y Colombia (Rappaport, 2000), los piqueteros y asambleas barriales en Argentina (Lewkovics, 2002; Ivern, 2007).

\section{Balance: las dimensiones subjetivas de la acción colectiva}

¿Qué implicaciones tienen los anteriores balances bibliográficos y elaboraciones conceptuales en torno al lugar de lo subjetivo en la acción colectiva y la subjetividad como perspectiva emergente para la investigación de los movimientos y luchas sociales? A partir de la revisión expuesta y de mi experiencia en el estudio de organizaciones y movilizaciones urbanas, se puede reconocer qué lugar ocupan las dimensiones subjetivas en los diversos niveles y planos de la acción colectiva y de qué modo esta puede abordarse como constituida y constituyente de subjetividad.

Las teorías predominantes sobre las organizaciones y las luchas sociales son planas y homogeneizantes, simplificadoras de la compleja realidad de sus dinámicas constitutivas (Pliego, 1997). Construir modelos analíticos que den cuenta de la complejidad de la acción colectiva, implica considerar tanto los factores y mediaciones estructurales como sus propios dinamismos constituyentes. La comprensión de las tensiones y problemas que les dan origen, de los actores que las conforman y que se forman en ellas, los repertorios de organización y movilización, así como de sus incidencias sociales y políticas, deben considerar las intenciones, motivaciones y sentidos que las orientan, la experiencia compartida y sentido común que generan, las ideas y valores que asumen, así como de los imaginarios culturales y utopías que las nutren (Torres, 2007).

Aunque el origen de la acción colectiva urbana está relacionado con las contradicciones estructurales que definen la organización del modo colectivo en la ciudad (Castells, 1980) y con las condiciones políticas y culturales del momento, existe un conjunto de instancias y procesos que median entre las condiciones estructurales y la acción organizada. Entre otras mediaciones socioculturales tenemos: la vida cotidiana de los sujetos, la red de relaciones de sociabilidad a nivel local, las tradiciones asociativa de los pobladores y la que se generan, las coyunturas internas de la evolución del asentamiento, las oleadas generacionales, los tipos de relación establecidas con otros agentes sociales y el Estado, así como la cultura política previa y emergente entre los pobladores (Torres, 1994).

En todos los procesos constitutivos de identidad colectiva, de actores sociales y de acción colectiva confluyen condiciones políticas y sociales estructurales, procesos generados por la propia experiencia asociativa y de lucha, y dimensiones subjetivas previas e instituidas por el movimiento. Así, en el análisis de experiencias de organización y movilización popular urbana, es necesario considerar:

1. El contexto histórico, en sus dimensiones estructural y coyuntural.

2. El contexto territorial en el cual se manifiestan las tensiones estructurales y coyunturales y son percibidas y elaboradas por la gente desde sus marcos interpretativos (cognitivos, valóricos e ideológicos).

3. Los vínculos de solidaridad entre los actores, que dan una base comunitaria a los movimientos, así como de unas dinámicas organizacionales y estrategias que estructuran la acción colectiva.

4. La formación-siempre abierta y conflictiva- de identidades y solidaridades que garantizan la unidad y continuidad de las organizaciones y luchas.

5. Las formas y modalidades de movilización colectiva que hacen visible el movimiento.

6. Su incidencia tanto en la coyuntura inmediata en la que actúan como en el conjunto de la sociedad.

Sin pretender agotar exhaustivamente cada una de los anteriores planos de análisis, a continuación los presento, destacando el lugar de la subjetividad en su abordaje: 1. Los factores estructurales que, aunque no la determinan, permiten comprender las 
condiciones de su emergencia; 2. El territorio como espacio en el que se forma el tejido social y las identidades vecinales; 3 . La vida cotidiana, en la que se perciben y asumen los conflictos sociales y se llevan a cabo las experiencias, las tácticas y las estrategias para afrontarlos; 4. Las dinámicas asociativas, en torno a las cuales se construyen nuevas relaciones, valores y orientaciones; 5 . La movilización colectiva y las expresiones manifiestas de protesta y 6 . Su incidencia social y cultural.

\section{Los factores estructurales y estructurantes}

Así no sea una condición suficiente, la acción colectiva urbana tiene como trasfondo la existencia de conflictos y contradicciones en las estructura sociales y políticas urbanas, las cuales, a su vez, están relacionadas estrechamente con el contexto societario más amplio en el que se generan. La sociología urbana marxista, en particular el catalán Manuel Castells, ha hecho valiosos aportes al respecto. Sus estudios sobre las políticas urbanas y la acción colectiva en la ciudad, siempre incorporan las condicionantes estructurales que están en su base. La ciudad, como producto histórico, evidencia los intereses sociales en pugna en un contexto histórico dado: "la histórica desigualdad en términos de renta, inherente al capitalismo se expresa en otras inequidades sociales relacionadas con la consecución de vivienda, la accesibilidad, uso y gestión de ciertos servicios colectivos sociales y culturales" (Castells, 2001).

Por otro lado, es sabido que en el siglo XX, como estrategia para conjurar las crisis económicas y las revoluciones sociales, en las sociedades capitalistas, al Estado se le asignó la responsabilidad de asumir los sectores menos rentables, pero necesarios para la actividad económica de atenuar los conflictos sociales. Así, incluso en la implantación del modelo neoliberal, el Estado dirigió la planificación urbana, generó políticas de vivienda, asumió la prestación de los servicios públicos y sociales y en algunos casos, el apoyo a las actividades culturales y deportivas en las ciudades (Castells, 2001). Esta intervención del Estado en la organización del consumo colectivo y las políticas culturales de la ciudad politizó la cuestión urbana. Por un lado, porque su actuación, así sea de carácter económico, está marcada, sobre todo, por una lógica política por el otro, porque al asumirse como garante de los derechos sociales de la población, el Estado se convirtió en el referente de casi todas las demandas y luchas urbanas.

\section{Territorios populares, tejido social e identidades colectivas}

El estudio y apoyo a la acción colectiva urbana debe remitirnos a la organización de la vida cotidiana de la gente y a los espacios en torno a los cuales construye sus vínculos sociales más significativos y elabora sus representaciones sobre sí mismos y sobre los demás; a los territorios en los que configuran sus solidaridades e identidades básicas y desde los cuales se relaciona con la ciudad. Para el caso de los pobladores urbanos de las ciudades de América Latina, dicho lugar ha sido el barrio; su historia es la historia de la incorporación de los inmigrantes a la vida urbana, de su lucha por el derecho a la ciudad y de su constitución como referente de sentido de pertenencia principal de sus habitantes; en un contexto de precaria e inestable vinculación laboral, su identidad social no ha estado marcado por el mundo del trabajo, sino por su experiencia como vecinos de un barrio o sector de la ciudad (Torres, 1994 y 2007).

Refugio de inmigrantes, lugar donde se desarrollan diferentes estrategias de sobrevivencia y resistencia a los embates de la pobreza y la exclusión, en el cual también se establecen relaciones personales más intensas y duraderas, difíciles de lograr en el mundo del trabajo. En la fase fundacional de los barrios, se recrean relaciones de compadrazgo y el paisanaje, en la casa se recibe a los familiares recién llegados del campo y se realizan bazares en los que se preparan productos de las regiones de origen. Estos vínculos de vecindad, compadrazgo, amistad $y$ afinidad cultural y generacional van formando una malla de relaciones que pueden leerse como redes sociales. "las redes sociales son formas de interacción, intercambio y reciprocidad que están orientadas a satisfacer ciertas necesidades de los grupos, sean afectivas, comunitarias, políticas, culturales, etc;" (Bolos, 2000, p. 37). Las organizaciones están sostenidas por estas redes informales que facilitan o limitan su actuación; la acción colectiva se inserta en las redes previas y las amplía; "crea vínculos donde no los había, agrega comportamientos al repertorio de la acción colectiva, transforma valores, crea o modifica imaginarios" (Espinoza, 1999, p. 213).

En el territorio, también sus pobladores constituyen identidades sociales. El barrio mismo es referente de identidad -en la medida que sus pobladores al construirlo, habitarlo y, muchas veces, defenderlo como territorio- generan lazos de pertenencia que 
les permite distinguirse frente a otros colectivos sociales de la ciudad (Illanes, 1993). También en él, se construyen diferentes identidades colectivas que expresan la fragmentación y las diferencias propias de la vida urbana contemporánea. Pero si bien la identidad barrial se alimenta de la experiencia compartida en la ocupación, producción y uso de un espacio, ésta no se agota en lo territorial. La identidad vecinal, además de experiencia intersubjetiva, es arena social en la que se definen diferentes actores luchan por la apropiación del territorio; "las identidades vecinales, además de ser una construcción social y cultural y un espacio de relaciones, es una arena de conflicto" (Safa, 1998, p.158).

\section{Vida cotidiana, elaboración de necesidades y experiencia}

En el proceso de conformación, apropiación y transformación del territorio transcurre la cotidianidad de sus pobladores por medio de las prácticas e interacciones subjetivas consuetudinarias, mediadas por el lenguaje. Es en la lucha diaria por la sobrevivencia cuando perciben los efectos de la exclusión, la pobreza y el desempleo, como experiencia compartida de precariedad, carencia y calamidad; donde la memoria y experiencia compartida conversan con los más cercanos (familia, vecinos, allegados) sobre dichas situaciones, valorándola o no como vejación, injusticia o agravio moral. Abordar la manera en que los colectivos populares definen sus necesidades y las tramitan como demandas, reivindicaciones, intereses o derechos requiere reconocer las mediaciones simbólicas, sociales y políticas que lo posibilitan. Ello exige estudiar procesos de atribuciones de significados mediante los cuales una ausencia se define como carencia y necesidad y por las cuales ciertas acciones sociales se definen como en correspondencia con los intereses de una colectividad (Sader, 1993, p.75).

Las necesidades son el sustrato más elemental de la relación entre la objetividad y subjetividad; es el cruce entre la existencia de una carencia material o simbólica y su percepción como tal por parte de unos sujetos desde su memoria, su visión de futuro. No sólo aluden a la sobrevivencia material, sino también a la necesidad del colectivo a reproducirse como tal. Por ello, la necesidad no es objetividad en el sentido de materialidad, sino objetividad que es construida según representaciones dadas (Zemelman, 1991). Los pobladores definen sus necesidades y las reelaboran como reivindicaciones, demandas o derechos y las enfrentan de diversos modos por medio de procesos en los que intervienen diferentes mediaciones culturales, sociales y políticas.

Las necesidades compartidas no generan, de modo natural, ningún tipo de acción colectiva. La cotidianidad popular también es el escenario donde la gente despliega sus esfuerzos y voluntades para afrontarlas. Es el plano de las experiencias en donde se evidencia la transformación de la realidad tanto objetiva como subjetiva y donde se da cuenta del potencial de la transformación de lo deseable en lo posible... (Zemelman, 1992). Así, la solución de las necesidades percibidas puede ser asumida de modo individual, familiar o colectivo, de manera ocasional o permanente, de forma desestructurada u organizada. Esta experiencia de resolución, de problemas comunes, también pasa por el entramado de creencias, representaciones y universos simbólicos previos, por la valoración de las alternativas que les ofrece el nuevo contexto y por la influencia de los agentes externos.

En la cotidianidad de los sectores populares se reproducen los discursos y prácticas hegemónicas, pero también donde emergen las tácticas de resistencia a la dominación y la exclusión. Allí se activan imaginarios colectivos y se van generando saberes, tácticas y estrategias para resguardarse de la mirada y las acciones de los poderosos. Esta sabiduría popular de resistencia se expresa en el terreno de la tradición oral y la imaginería popular por medio de los cuentos populares, el humor, la picardía, el rumor, los juegos de palabras y las inversiones simbólicas (Scott, 2000). Habría que reconocer en cada contexto social y cultural, cuáles son los mecanismos más frecuentes de interiorización de los valores y relaciones dominantes, así como las formas de resistencia desde el anonimato de la vida diaria y de las maneras en que se incorporan en los procesos organizativos y en las acciones de protesta.

\section{La conformación del tejido asociativo}

En el análisis de la acción colectiva urbana es imprescindible considerar los procesos organizativos por medio de los cuales los pobladores articulan voluntades, capacidades, relaciones y propósitos, para garantizar estrategias de mayor permanencia a sus problemas compartidos. Ya sea por sus representaciones y experiencias previas en las maneras de resolver problemas, por su magnitud o naturaleza, por 
el agotamiento o insuficiencia de otras estrategias, por la existencia de canales institucionales o agentes externos que promueven la acción organizada (ya que generalmente los pobladores estructuran sus acciones mediante procesos organizativos).

Las organizaciones se diferencian de las acciones puntuales promovidas por redes sociales o grupos ad hoc, por su permanencia en el tiempo, grado de estructuración interna, establecimiento de propósitos a mediano y largo plazo; también, porque éstos suponen una lectura más sistemática de las necesidades, de la elaboración de un horizonte común y la disposición de unos recursos y unas estrategias permanentes para alcanzarlo. En términos de Pliego (1997), las organizaciones sociales poseen programas, entendidos como "unidades de estructuración mínima de las actividades que desarrolla una organización, de acuerdo con una definición colectivamente compartida de objetivo, metas, recursos y procedimientos".

En la medida en que las experiencias asociativas se consolidan, las acciones se tornan estables y orientadas en torno a proyectos. Éstos resuelven en un nivel más complejo la tensión entre necesidad y utopía, entre presente y futuro posible. El proyecto evidencia una conciencia de metas previstas y el despliegue de prácticas para conseguirlas; supone una elaboración colectiva de un horizonte histórico común, de una identidad más estable y reflexiva. Según Palma (1995), estaríamos en el plano de las prácticas intencionadas, diferentes a las experiencias vividas e interpretadas sólo desde el sentido común de los colectivos populares.

La acción de las organizaciones enriquece el tejido social, amplía la lectura que la gente hace de sus problemas y, por tanto, de sus posibilidades de solución; también contribuyen al fortalecimiento o emergencia de identidades sociales y facilita la movilización social. Las organizaciones son espacios de institucionalización de formas de solidaridad social presentes en la cotidianidad popular, son nudos del tejido local popular desde las cuales los pobladores se conforman como actores con capacidad de ser reconocidos por otros actores urbanos.

Otro nivel asociativo es la creación de redes o espacios de coordinación permanente entre grupos y organizaciones. Ya sea en una misma zona o localidad, en torno a un campo temático común, como la salud, la educación popular, el trabajo con niños o por iniciativa de algún actor estatal o social "externo", son cada vez más comunes estas experiencias de asociación de segundo y tercer grado. Este nivel organizativo generalmente supone una lectura más estructural del campo problemático en el cual se actúa, así como una expansión del horizonte utópico que las anima (transformar políticas, afectar significados públicos frente a un tema, proponer nuevos modelos sociales).

\section{La movilización: de la protesta a las redes en movimiento}

De vez en cuando los pobladores, por fuera o por medio de sus organizaciones, desde sus territorios o por fuera de ellos, deciden acudir a "las vías de hecho" para obtener solución a sus problemas, denunciar una medida adversa, sumarse a una protesta mayor o expresar solidaridad con otros actores. Este es el ámbito de la movilización colectiva, la cual ha sido asumida por muchos como el mejor termómetro de los movimientos sociales. Sin embargo, estas formas visibles de acción colectiva no pueden comprenderse por fuera de los tejidos sociales y asociativos que las posibilitan; la movilización requiere una preparación previa, una coordinación de esfuerzos, unos niveles de conciencia entre sus promotores y unas demandas o iniciativas más elaboradas.

La conformación histórica de los movimientos sociales se articula en diferentes planos temporales (Villasante, 1994). En general, se incuban silenciosamente en la vida cotidiana de los colectivos en su lucha diaria en torno a sus necesidades; ello va conformando lentamente (larga duración) vínculos estables, habitus y memoria colectiva de resistencia; estas redes sociales son el caldo de cultivo para el surgimiento y actividad de las asociaciones (media duración) y para el estallidos de actos de inconformismo (corta duración). No hay que limitar el análisis de la acción colectiva a sus luchas manifiestas, pues se puede quedar atrapado en el tiempo corto, dejando por fuera el tiempo largo, "ese trasfondo, al cual se incorporan como memoria, aprendizaje o condición estructural, una vez finalizado el conflicto" (Espinoza, 1999, p. 48)

No hay que confundir las organizaciones con las movilizaciones que promueven o en las cuales participan; se necesitan mutuamente, pero son diferentes: si hay movilización, la asociación queda desbordada; y si la asociación se consolida, la movilización queda controlada. Las organizaciones necesitan 
movilizarse para mantenerse como movimiento, pero sobreviven a estas acciones, conformando una dimensión menos visible pero más sólida de los movimientos sociales. En los territorios populares se gestan y realizan diversas expresiones de protesta popular; en unos casos, orientadas a ejercer presión para la consecución de un bien urbano como una vía, el acueducto o de las redes de energía; en otros, para oponerse a una medida adversa que perjudica la integridad física o cultural de un barrio, zona de la ciudad o del país; finalmente, los habitantes de los barrios se suman a actos de protesta convocadas por otros actores y que expresan el inconformismo frente a la situación económica de las clases trabajadoras o contra una medida o política gubernamental que lesiona sus derechos.

\section{La incidencia de la acción colectiva}

En todos los casos, las protestas urbanas no sólo pretenden obtener solución a sus demandas, sino también elevar los niveles de compromiso de sus actores sensibilizar a la opinión pública de la justeza de tales reivindicaciones y atraer nuevas bases a los movimientos. Por eso es que las acciones colectivas manifiestas tienden a ser expresivas, a revestirse de elementos simbólicos que afirman identidad y

\section{Bibliografía}

Archila, M. (1995). Tendencias recientes de los movimientos sociales. En F. Leal (comp.), En búsqueda de la estabilidad perdida. Bogotá: Tercer Mundo.

Archila, M. (1998). Poderes y contestación. Controversia, 173.

Blumer, H. (1946). Collective behavior. En Lee (edit.), New Outlines of the principles of Sociology. Nueva York: Barnes and Noble.

Bolos, S. (1999). La constitución de actores sociales y la política. México: Plaza y Valdez.

Bonilla, J. y García, E. (1998). Los discursos del conflicto. Bogotá: Pontificia Universidad Javeriana.

Calvillo, M. y Favela, A. (1995). Los nuevos sujetos sociales. Una aproximación epistemológica. Sociológica, 28.

Casanova, J. (1991). La historia social y los historiadores. Barcelona: Editorial Crítica. sensibilizan a la ciudadanía; también, les resulta importante, hacerse visibles por medio de los medios de comunicación y de otras acciones públicas.

Por ello, un aspecto que hoy se desataca de los movimientos es su incidencia cultural y política sobre el conjunto social. Más allá de sus activistas, militantes y simpatizantes, los movimientos que reivindican la equidad de género, los derechos de los homosexuales, de grupos étnicos y generacionales, han logrado calar en la conciencia y la cultura de amplios sectores de la población, modificando actitudes, representaciones y hábitos sociales. Muchas personas incorporan en su vida cotidiana algunos valores e ideas provenientes de dichos movimientos, así no sepan el origen de tales parámetros.

Es en este sentido que Melucci (1999) destaca el carácter "profético" de los movimientos sociales (anuncian nuevas formas de vida que ya pueden irse realizando), y otros autores como Escobar, Dagnino y Gruesso (2001) señalan que éstos son generadores de culturas políticas que contribuyen a la democratización de la sociedad. Ello nos permite confirmar lo anunciado al comienzo de este artículo: los movimientos sociales han sido instituyentes de buena parte de los rasgos progresistas de las sociedades contemporáneas. Џ!

Castells, M. (1980). Los movimientos sociales urbanos. México: Siglo XXI.

Castells, M. (1981). La cuestión urbana. México: Siglo XXI.

Castells, M. (1986). La ciudad y las masas. Madrid: Alianza Universidad.

Castoriadis, C. (1977). Ontología de la creación. Ensayo $y$ Error.

Castoriadis, C. (2003). La institución imaginaria de la sociedad. Vol. 2: El imaginario social y la institución. Buenos Aires: Tusquets.

Castoriadis, C. (2004). Sujeto y verdad en el mundo histórico social. Seminarios 1986-1987. Buenos Aires: Fondo de Cultura Económica.

Chihu, A. (2008). El análisis de marcos en la sociología de los movimientos sociales. México: Miguel Angel Porrúa-UAM, Iztapalapa. 
Chanquía, D. (1994). Para investigar procesos de constitución de sujetos sociales. Suplementos, 45.

Cohen, J. (1995). Estrategia e identidad: nuevos paradigmas teóricos y movimientos sociales contemporáneos. Sociología y Política, 6.

Cohen, J. y Arato, A. (2001). Sociedad civil y teoría política. México: Fondo de Cultura Económica.

De Souza, B. (1994). Subjetividad, ciudadanía y emancipación. El Otro Derecho, 15.

Elster, J. (1979). Ulises y las sirenas. México: Fondo de Cultura Económica.

Elster, J. (1989). El cemento de la sociedad. Barcelona: Gedisa.

Escobar, Arturo y Alvaro Pedroza (1996). Pacífico: ¿desarrollo o diversidad? Estado, capital y movimientos en el Pacífico Colombiano. Bogotá: Cerec - Ecofondo

Escobar, A., Álvarez, S. y Dagnino, E. (2001). Política cultural y cultura política. Una nueva mirada a los movimientos sociales latinoamericanos. Bogotá: Taurus-Icanh.

Espinoza, V. (1985). Experiencias y perspectivas del movimiento popular chileno. Cuaderno Ciudad y Sociedad; Problemas Urbanos del Tercer Mundo, II.

Fried, D. (1995). Nuevos paradigmas, cultura y subjetividad. Buenos Aires: Paidós.

Gadea, C. (2004). Acciones colectivas y modernidad global. El movimiento zapatista. Toluca: UAEM.

Goffman, E. (1974). Frame analysis. Cambrdige: Harvard University Press.

Gusfield, J. (1994). La reflexividad de los movimientos sociales: revisión de las teorías sobre sociedad de masas y el comportamiento colectivo. En E. Laraña y J. Gustielf, Los nuevos movimientos sociales: de la ideología a la identidad. Madrid: CIS.

Harnecker, M. (1980). Los conceptos elementales de materialismo histórico. Cuadragésima edición, Bogotá: Siglo XXI Editores.

Ibáñez, T. (1994). Psicología social constructivista. Guadalajara: Universidad de Guadalajara.

Illanes, M. (1993). La cuestión de la identidad y la historiografía popular. En Historias locales y democratización. Santiago: Eco.
Ibarra, P. y Tejerina, B. (1999). Movimientos sociales, transformaciones políticas y cambio cultural. Madrid: Trotta.

Ivern, A. (2007). Autoorganización, proyectos compartidos y procesos de aprendizaje. Buenos Aires: Editorial SB.

Jaidar, I. (2003). Tras las huellas de la subjetividad. México: UAM.

Johnston, H., Laraña, E. y Fustielf, J. (1994). Cultura, ideologías y vida cotidiana en los nuevos movimientos sociales. En E. Laraña y J. Gustielf, Los nuevos movimientos sociales: de la ideología a la identidad. Madrid: CIS.

Laclau, E. (1987). Los nuevos movimientos sociales y la pluralidad de lo social. Revista Foro, 4.

Laraña, E. (1999). La construcción de los movimientos sociales. Madrid: Alianza Editorial.

León, E. (1995). La experiencia en la construcción del conocimiento social. En Determinismos y alternativas en las ciencias sociales de América Latina. Caracas: UNAM-Nueva Sociedad.

Lewkovics, I. (2002). Sucesos argentinos. Cacerolazo y subjetividad postestatal. Buenos Aires: Paidós.

Luminato, S. (1995). La función de los valores en el pensamiento filosófico latinoamericano. En Determinismos y alternativas en las ciencias sociales de América Latina. Caracas: UNAM-Nueva Sociedad.

Maffesoli, M. (1990). Tiempo de las tribus. Barcelona: Icaria.

McAdam, D., McCarthy, J. y Zaldd, M. (1999). Movimientos sociales: perspectivas comparadas. Madrid: Istmo.

Marx, C. (1975). La lucha de clases en Francia de 1848 a 1850. Moscú: Editorial Progreso.

Marx, C. (1978). El 18 brumario de Luis Bonaparte. Pekín: Editorial Lenguas Extranjeras.

Marx, C. (1980). La guerra civil en Francia. Moscú: Editorial Progreso.

Marx, C. y Engels, F. (1970). Manifiesto del partido comunista. Moscú: Editorial Progreso.

Meluccil, A. (1976). La teoría de los movimientos sociales. En Teoría y forma de la acción colectiva. Milán: Etas Libri. 
MelucciI, A. (1985). The symbolic challenge of contemporary movements. Social Research, 4(52).

Meluccil, A. (1995). El conflicto y la regla: movimientos sociales y sistemas políticos. Sociológica, 28.

MelucciI, A. (1989). Nomads of the present. Filadelfia: Temple University Press.

Meluccil, A. (1994). ¿Qué hay de nuevo en los nuevos movimientos sociales? En E. Laraña y J. Gusfield, Los nuevos movimientos sociales: de la ideología a la identidad. Madrid: CIS.

MelucciI, A. (1995). The process of collective identity. En H. Johonston y Klandermas (ed.), Social movements and culture. Minneapolis: University of Minessota.

MelucciI, A. (1999). Acción colectiva, vida cotidiana y democracia. México: El Colegio de México.

Moscovisci, S. (1996). Psicología social. Madrid: Paidós.

Moore, B. (1974). Los orígenes sociales de la dictadura y la democracia. Barcelona: Península.

Moore, B. (1996). La injusticia: bases sociales de la obediencia y la rebelión. México: UNAM.

Munk, G. (1995). Algunos problemas conceptuales en el estudio de los movimientos sociales. Revista Mexicana de Sociología, 3.

Múnera, L. (1998). Rupturas y continuidades: poder y movimiento popular en Colombia 1968-1988. Bogotá: Cerec.

Neveu, E. (2000). Sociología de los movimientos sociales. Quito: Abya Yala.

Obershall, A. (1973). Social conflict and social movements. Nueva York: Prentice Hall.

Olson, M. (1992). La lógica de la acción colectiva. México: Limusa-Noriega.

Pichon Riviere, E. (1985). Psicología de la vida cotidiana. Buenos Aires: Editorial Nueva Visión.

Pliego, F. (1997). Estrategias de participación de las organizaciones sociales: un modelo de interpretación. Sociedad Civil, 1(II).

Rappaportt, J. (2000). La política de la memoria. Popayán: Universidad del Cauca.

Ricoeur, P. (2003). La memoria, la historia, el olvido. Madrid: Trotta.

Sabucedo, J. M., Grossi, J., Roríguez, M. y Fernández, C. (s. f.). Los movimientos sociales: discurso y acción política. Revista Universidad de Guadalajara.
Sader, E. (1993). Cuando nuevos personajes entran en escena. Río de Janeiro: Paz e Terra.

Safa, Patricia (1998). Vecinos y vecindarios en la Ciudad de México. México DF: Ciesas - UAM - Miguel Porrua editores

Sánchez Cafdequi, C. (1999). Imaginación y sociedad: una hermenéutica creativa de la cultura. Madrid: Tecnos-Universidad Pública de Navarra.

Scott, J. (2000). Los dominados y el arte de la resistencia. México: Era.

Smelser, N. (1995). Comportamiento colectivo. México: Fondo de Cultura Económica.

Tarrow, S. (1997). El poder en movimiento. Madrid: Alianza Editorial.

Tejeiro, J. (2007). La rebelión permanente. La Paz: PIEBPlural.

Thompson, E. (1981). Miseria de la teoría. Barcelona: Editorial Crítica.

Thompson, E. (1984). Tradición, revuelta y conciencia de clase. Barcelona: Editorial Crítica.

Tilly, C. (1995a). Los movimientos sociales como agrupaciones históricamente específicas de actuaciones políticas. Sociológica, 28.

Tilly, C. (1995b). Modelos de y realidades de la acción colectiva popular. En Intereses individuales y acción colectiva. Madrid: Editorial Pablo Iglesias.

Torres Carrillo, A. (1994). Experiencias organizativas urbanas y constitución de sujetos sociales. Aportes, 40. Bogotá: Dimensión Educativa.

Torres Carrillo, A. (1999). Organizaciones y luchas urbanas en América Latina. Controversia, 175.

Torres Carrillo, A. (2000). Sujetos y subjetividad en la educación popular. Pedagogía y Saberes, 15. Bogotá: Facultad de Educación-Universidad Pedagógica Nacional.

Torres Carrillo, A. (2002). Reconstruyendo el vínculo social. Movimientos sociales, organizaciones populares y constitución de sujetos colectivos. Bogotá: Unad.

Torres Carrillo, A. (2006). Subjetividad y sujeto como perspectiva de investigación social y educativa. Revista Colombiana de Educación, 50.

Torres Carrillo, A. (2007). Identidad y política de la acción colectiva. Bogotá: Universidad Pedagógica Nacional. 
Touraine, A. (1978). La voz y la mirada. París: Seuil.

Touraine, A. (1987). El regreso del actor. Buenos Aires: Editorial Eudeba.

Touraine, A. (1997) ¿Podremos vivir juntos? México: Fondo de Cultura Económica.

Turner, R. y Killan, L. (1986). Collective behavior. Englewood Cliffs, NJ: Prentice-Hall.

Villasante, T. (1991). Movimiento ciudadano e iniciativas populares. Cuadernos de Noticias Obreras, 16.

Villasante, T. (1994). Las ciudades hablan. Identidades y movimientos sociales en seis metrópolis latinoamericanas. Caracas: Nueva Sociedad.
Zemelman, H. (1987). Conocimiento y sujetos sociales. México: El Colegio de México.

Zemelman, H. (1992). Los horizontes de la razón. Dialéctica y apropiación del presente. Barcelona: AnthroposEl Colegio de México.

Zemelman, H. (1996). Problemas antropológicos y utópicos del conocimiento. Jornadas, 126.

Zemelman, H. (1997). Subjetividad: umbrales del pensamiento social. Barcelona: Anthropos.

Zemelman, H. (1998). Sujeto: existencia y potencia. Barcelona: Anthropos.

Zemelman, H. y León, E. (1997). Subjetividad: umbrales del pensamiento social. Barcelona: Anthropos. 